\title{
Features of Functioning Economic Metaphorical Terminology in Modern Advertising Discourse
}

\author{
Yulia Nikolaevna Ebzeeva ${ }^{1}$, Liliya Faylasovna Sultanova ${ }^{2}$, Karpis Sarkisovich \\ Anumyan $^{1}$, Irina Sovetovna Karabulatova ${ }^{1,3, *}$, Olga Vladimirovna Mamatelashvili ${ }^{4}$
}

\author{
${ }^{1}$ Department of Foreign Languages, Philological Faculty, Peoples' Friendship University of Russia (RUDN-university), \\ Moscow, Russia \\ ${ }^{2}$ Department of Continuing Professional Education, Bashkir Academy of Public Administration and Management under \\ the Head of the Republic of Bashkortostan, Ufa, Russia \\ ${ }^{3}$ Russian Academy of Natural Sciences, Moscow, Russia \\ ${ }^{4}$ Department of Economic security, Ufa State Petroleum Technological University, Ufa, Russia \\ * Corresponding author. Email: radogost2000@msil.ru
}

\begin{abstract}
Introduction. Economics and linguistics are United by the dualism of human nature: word and action. Modern society clearly demonstrates the convergence of the spheres of Economics and linguistics, as civilization develops in a digital format.

Object of research: terms-metaphors in the language of Economics. The concepts of Economics play an important role in the complex process of cognition of changes in the life of society, they are implemented as new meanings of familiar words, forming a new holistic system. Close attention is paid to the functioning of economic terminology in modern advertising discourse.

The subject of the study: language / speech implementation of the mechanism of influence of economic advertising forms in the mass-media economic advertising discourse.

Our hypothesis. Interest in the relationship between Economics and linguistics is since Homo sapiens was replaced by Homo Economicus, a rational subject making rational decisions. In this regard, the verbalization of economic concepts is changing. We analyze only the used algorithms of metaphorization of economic concepts that influence the verbal behavior of modern man. "Dry" is an economic term, through the metaphor becomes more understandable for the ordinary native speaker.

Methodology. Methods of applied linguistics for the analysis of language metaphors used in economic terminology in the mass-media economic advertising discourse.

Applications of this study: applied linguistics, economic terminology, language theory, psycholinguistics, social Economics.

Novelty/Originality of this study: We propose to consider the semantic field of the economic term as the sphere of existence of the latter in the subjective lexicon, and through it in the unified information base of a person as a carrier of language consciousness, which is an integral part of the individual's worldview and is formed from the complex interaction of his knowledge.
\end{abstract}

Keywords: economics, linguistics, terminological system, metaphor of economic

\section{INTRODUCTION}

It is known that modern society is experiencing a flowering of consumption. In this regard, a special picture of the world of Economics should become a methodological tool that can guide the development of modern economic processes and their scientific research. One of the most important is that there is a clear correlation between a country's economic achievements, culture and language. All this strongly requires approaching the metaphor of the economic lexicon as a special linguistic sign, which is, on the one hand, an important element of the linguistic semiotic system, on the other-a language construct that correlates with the signs of this and other semiotic systems. Many important economic terms carry a double burden: "what is" and "what should be". Moreover, these two sides, as a rule, are difficult to distinguish, often there is an invisible "slipping" from positive to the normative plane. Implicitly introduce a positive assessment of the respective phenomena. For example, the formal meaning of the concept of equilibrium as an optimal state in a certain sense often gives way to the notion of it as a good, desirable state in general. Waistband prices acquire "properties" right, good prices. The convergence of metaphorical pictures becomes a bright sign of today, it contributes to the creation of a holistic view of the changes in the events of the world economy. In this regard, we consider it necessary to describe the metaphors of the economic lexicon, which have a special symbolic character.

The developing meta-theoretical analysis of economic knowledge shows that the prospects for the development of Economics as a science largely depend on the rationalization, ordering, unification of existing concepts and terminological systems. Semantic analysis is based on the study of the meaning of individual units of term systems, i.e. terms. In Economics, the change of one 
conceptual scheme to other leads to a change in the meaning of economic terms, and in the framework of research programs, new terms arise; in the disciplinary units of knowledge, there is also a change and the emergence of new terms. Consequently, the meaning of all the subject terms of economic theory is determined by the whole context of the theory and changes with the change of this context under the influence of practice.

As many linguists claim today, language itself imposes a certain structure on reality $[1,2]$. Using concepts such as the revolutionary process, competitive selection, the functions of the entrepreneur, the equilibrium state, the optimal distribution, economists not only determine the analytical tools, but also set a way of seeing reality and relating to it. Linguistics "works" and a degree [3].

The modern economy is characterized by processes associated with the gradual exhaustion of the possibilities of using traditional resources to ensure economic growth, which is caused by the approximation of the physical limits of resource use, and a decrease in their efficiency. In this regard, the system of scientific knowledge in the field of innovation processes and new technologies should be a fundamental element of the modern model of economic growth.

Modern consumer society requires economic knowledge from members of society, which facilitate, as a rule, the process of acquiring something. In this regard, it becomes more diverse and advertising with economic terminology [4], which can be aimed at professionals and the broadest segments of the population.

Economics and linguistics are two spheres of science that unite people-acting and thinking. There is a clear correlation between a country's economic achievements, culture and language. This fact allows scientists to talk about a new scientific discipline of linguoeconomics [5-7], the development of which takes place in two directions from language to reality and from reality to language. At the same time, the motivation for economic activity of the population is clearly observed in the advertising discourse, which, in the fair opinion of N. D. Arutyunova, there is a speech immersed in life [8].

The abundance of consumer society leads modern man to believe that he is half a step away from the society of dreams [9], that any whim can be acquired. Along with the variety of products comes the variety of services that require knowledge of economic terminology.

On the basis of a comprehensive study of all the processes associated with the integration and interaction of Economics and linguistics, as well as the analysis of the dictionary of these Sciences, the assumption is made about the prospects of studying the economic field in modern advertising, which is not only based on the knowledge of previous eras, but also based on domestic economic, political and other models that are correct in relation to the formed conceptosphere.

Logical positivism shows a distinct tendency to exaggerate the role of precision and rigor in the development of scientific knowledge. Logical-mathematical accuracy was considered by logical positivists and their researchers as one of the highest values of scientific knowledge. In this context, the analysis of everyday language reveals the "background" knowledge of the world, the nature of the reduction of semantic components, some common correspondences of meanings and meanings of approaches and actions, speech acts, etc. the Role of the language context has become particularly clearly visible in the economy.
In economics, the role of the language context is particularly clearly visible, the connection of language with the extra-language context of its use, without which it is impossible to solve questions of meaning as usage and other problems related to contextual theory of meaning. That is why the adequacy or inadequacy of the context of the activity, and on the other - the depth and validity of linguistic expressions are important aspects of economic theory.

The language of economic theory is created primarily for the fixation and transfer of scientific information: the cognitive function comes to the fore. Words and concepts are the realities of cultural and professional consciousness, the level from which the initial fixation of knowledge begins, its understanding and interpretation. Here, in thinking, a first layer of contradictions arises - "words" and "things", the resolution of which leads to an important condition for the accuracy of knowledge - the formation of word-terms with a certain semantic structure (as unequivocal as possible), empirically verified and theoretically deeply grounded.

The understanding of metaphors in a broad sense and includes metaphor and metonymy, and it's a kind of synecdoche. Metaphor itself as a sign construct has unlimited possibilities of generation, preservation and transmission of information, at the same time metaphor as an element of the whole - a linguistic semiotic system serves as the basis for extrapolation of the semiotic method to the metaphorical representation of economic concepts.

The presented research relates to further development of the problem of integration of Sciences. Globalization and interactive augmented reality contribute to the expansion of existing ideas about the role of the economy in life and the linguistic picture of the human world. In addition, the analysis of the" inner content "of economic terms in everyday and professional language consciousness makes it possible to present the term as a multidimensional linguistic reality, rather than a "emasculated word". We propose to consider the semantic field of the economic term as the sphere of existence of the economic term in the subjective lexicon, and through it in the unified information base of a person as a carrier of language consciousness, which is an integral part of the worldview of the individual and is formed from the complex interaction of his knowledge.

The dependence of economic relations on the historical development of society (formations / system, progress/regression, socialism / democracy, etc.) is reflected in the advertising discourse using economic terminology. Russian economic terminology covers the main conceptual areas and concepts of Economics. In the course of the study, the influence of economic processes occurring in society on the linguistic picture of the world is revealed. The sociocultural situation is the most important factor in the functioning and development of economic terminology. The current economic situation is characterized by the following features: dialogue, horizontal economic relations and the ratio of "man-economy". For the presentation of economic terminology in advertising, the latter parameter is of importance.

New economic relations in the era of democratization of language caused the emergence of a new advertising discourse with an economic component, covering not only the economy, but also all spheres of human life. As a result, the anthropocentric approach to the study of economic terminology seems to be the most relevant in the process of studying its functioning in modern advertising discourse, since within the boundaries of this approach, the following 
relations can be taken into account: personality $\leftrightarrow$ economy, person $\leftrightarrow$ economy, society $\leftrightarrow$ economy, politics $\leftrightarrow$ economy, etc. Modern economic terminology, presented in modern advertising discourse, is characterized by the adequacy of the language to a specific cultural and historical era and economic and social relations.

The existing advertising discourse is potentially the basis for the integration of Economics and linguistics, as well as other Sciences. Real boundaries and levels of interaction between linguistics and Economics are observed in the ways of formation of new words.

The functioning of signs of economic terminology in certain cultural and historical conditions contributes to the creation of specific schemes of representation of economic terms in advertising discourse. The main ways of integration are as follows: the transfer of ideas and ideas from one area of knowledge to another (exchange) and the effective use of conceptual apparatus, methods and other cognitive means of some areas of science by others (the birth of a new currency).

\section{LITERATURE REWIEW}

The turn of the century is often marked by a change of aesthetic, ethical, scientific paradigms, and therefore is often perceived as the turn of the epochs. This study is different, so to speak, "anthroplasty" - anthropochemical and anthropoligie trends. And this means that in scientific research, in one way or another, the human factor itself is considered.

As you know, accuracy and rigor is the ideal of the language of science, which are achieved by the introduction of symbolic symbols (while maintaining a sufficiently pronounced "vagueness" of meaning) and the construction of calculus (absolute accuracy is not achieved).

Interest in the language of Economics as a special and professional language is primarily associated with the emergence in the 30 s of the XX century of the so-called "economic linguistics" $[10,11]$. At present, communication in the economy is one of the leading areas of linguistic research, which is due, on the one hand, to the increased internationalization of the economy and the need to diversify the economic supply and marketing of products, and on the other hand, the fact that the concept of economic activity involves a variety of aspects of its implementation.

The language of economic theory is created to capture and transmit scientific information: cognitive function comes to the fore. Words and concepts are the realities of cultural and professional consciousness, the level at which the initial fixation of knowledge, its understanding and interpretation begins [12]. In thinking there is a first layer of contradictions - "words" and "things", the resolution of which leads to an important condition and accuracy of knowledge-the formation of words-terms with a certain semantic structure (as far as possible unambiguous).

The frequent occurrence of metaphor in economic texts has been studied before us in connection with the axiological potential of metaphor and its function to strengthen the cumulative illocutionary power of utterance [13-16].

Researchers from different countries pay attention to the influence of language factors on the development of a particular field of activity, emphasizing the importance of creating leadership attitudes, empathy among staff [17-20]. First, the word plays a big role in emotional intelligence. It is quite controversial to say that the performance is necessary at work. Some researchers compare the work of a top Manager with a performance [21]. However, the artist after the performance returns to his reality, but the researchers-economists do not talk about changes. We believe that it is impossible to play and live all the time in a mask, so you cannot put equality between artist and Manager. We agree with the idea that an effective economy requires knowledge about cultural values. The verbalization of spiritual values in the economy contributes not only to the development of emotional intelligence in employees, but also ultimately increases sales. To present the goods beautifully, to link the history of the goods with culturally significant concepts-this makes the sales Manager a skillful master of words and culture in General. He becomes a preacher of cultural values through economic realities.

In the modern "linguistic turn" with emphasis on the language, its syntax, semantics, pragmatics, it is not about the world as such, not about being in its direct givenness, but about the correctness or incorrectness of linguistic statements owls, on the logical correctness of argumentation, understanding and interpretation in a functional approach to understanding the language: the meaning of a word is its use. Linguistic philosophy, based on the thesis "value is use", formulates a number of important research directions: the concept of "language games" and the principle of "family similarity" of Wittgenstein, the principle of intentionality with personal or motivational installation that influences the structure of language communication, including in psychology and psychiatry, and finally, understanding and interpretation in their "analytical" and "hermeneutical" tradition.

The analysis of theoretical material, as well as examples obtained by continuous sampling from Russian, English and French-language popular scientific texts, indicate the use of metaphors to represent the basic economic concepts of the State, the Market, Money, Crisis, Advertising, BREXIT, etc. The construction of an economically unified Europe, the role and place of France among the EU member States, regular meetings at the highest level, the development of economic cooperation, the foreign and domestic policy of Russia, which seeks to take a worthy place in the world economic community, all this is accompanied by the formation of new economic concepts-Globalization, the euro, the European Union, the European Parliament, Monopoly, etc.

It should also be noted that scientists have not come to a single definition of what a scientific concept means. This question remains today one of the most controversial in linguistics. In this paper, we define the economic concept as relating to the mental world; representing a form of thinking, which reflects the essential, i.e. sufficient for separation (isolation, generalization) signs of the object (phenomenon, event) of economic reality and expressed in language by means of signs.

It is no coincidence that researchers such as [22] consider the effect of top managers ' work given their emotional intelligence and creativity, which are articulated in a clear and concise manner.

The results of the analysis are based on the construction and study of formal languages with simple structure and poor content, as is found in the economic advertising discourse. In this case, we agree with researchers who argue that creating strong motivation through verbal means is a necessary link [23].

There are many definitions of metaphor (Aristotle, V. V. Vinogradov, J. V. Lakoff, A. A. Richardet, V. N. Telia, et al.). Our understanding of metaphor coincides with the definition formulated by S.A. Khakhalova: "by metaphor 
we understand multi-level units of secondary indirect nomination-nominative signs (words, phrases), predicative signs (sentences), complex predicative signs (texts) based on the transfer of the formative from a fictitious single (and maybe complex) denotation to a real single (complex) denotation, between which a common constant of comparison is found" [24]. The above definition characterizes the types of metaphor considered in this dissertation study (except for the texts-metaphors) and corresponds to our view of metaphor as a means of communication between the possible (fictitious) world of the author and the real, real world. The given definition characterizes the types of metaphor considered in the dissertation research (except for texts-metaphors) and corresponds to our view of the metaphor as a means of communication between the possible (fictitious) world of the author and the real, real world. We also analyze the use of Proverbs, since the latter are predicative signs of a phraseological character with metaphorical motivation. Before us the Proverbs have all the signs of a universal category of metaphor, namely: a) transfer of formativ with dummy denotation for real; b) associative similarity matching denotations; C) the dominance of secondary importance; g) the parallelism of the two complex denotations [24].

And only to the extent that these formal languages reflect the properties of the real languages of science or natural language, the results of their research can shed light on the features of the natural language. The language of economic theory has a complex structure. Its foundation, like any language, is natural language. Its central core is its own conceptual apparatus for the expression of empirical and theoretical economic information (language of observation, empirical and theoretical constructs), philosophical categories underlying a given theoretical system of economic knowledge, as well as concepts of related, interacting sciences that perform specific gnoseological functions. From the epistemological point of view, the language of economic theory is a education derived from a natural language, which has a deep cognitive-language specialization, with a special development of the verbalterminological component.

We consider economic communication in the enterprise as a situational context in which texts are immersed. The most part of activity at the enterprise is the communicative activity proceeding in the form of texts. The concept of text and its properties are therefore considered in their close connection with the economic activity of the enterprise and functional typical situations of activity in the enterprise.

Considering communication at the enterprise as one of the varieties of economic discourse, we so limit the scope of research and narrow the scope of the concept of economic communication to a set of spheres of activity of the enterprise, represented by a set of texts as communicative units representing the specifics of communicative activity at the enterprise. The specificity of communicative activity in the enterprise is set by the institutional framework of communication, the framework of special and professional communication, as well as a set of specific for each enterprise and its departments typical production and business situations. We consider economic communication in the enterprise as a situational context in which texts are immersed. The most part of activity at the enterprise is the communicative activity proceeding in the form of texts. The concept of text and its properties are therefore considered in their close connection with the economic activity of the enterprise and functional typical situations of activity in the enterprise.

Considering communication at the enterprise as one of the varieties of economic discourse, we so limit the scope of research and narrow the scope of the concept of economic communication to a set of spheres of activity of the enterprise, represented by a set of texts as communicative units representing the specifics of communicative activity at the enterprise. The specificity of communicative activity in the enterprise is set by the institutional framework of communication, the framework of special and professional communication, as well as a set of specific for each enterprise and its departments typical production and business situations.

\section{METHODOLOGY}

The aim of the work was to identify the main conceptual spheres of the economy with their peculiarities of representation in the language. Based on this, we solve such problems as to identify the concepts and ways of implementing economic concepts in the language; to determine the adequacy of the language to its cultural and historical era and economic relations; to study the impact of economic processes occurring in society on the linguistic picture of the world.

The statement of the stated theme serves as the basis for extrapolation of the semiotic method into the field of metaphorical representation of economic concepts and analysis of the latter in accordance with the three dimensions of semiosis developed by C. Morris. We investigate formal transformations and relations of signs in the system of language (syntactics); substitution of realities of the world of economy, its signification, categorization and conceptualization (semantics); expression of the relation of a person (society) to what is signified (pragmatics).

The object of this study is the economic metaphorical terminology used in modern advertising discourse. The concepts of Economics play an important role in the complex process of cognition of changes in the life of society, being realized in the text in the form of new words and meanings, forming a new subspace in the modern advertising discourse.

The subject of the study is the language / speech implementation of the mechanism of influence of economic advertising forms in mass-medial discourse on the material of economic advertising discourse in the media system.

The material for the study was the language units of economic terminology of the Russian language used in advertising discourse, dictionary interpretations of units, contexts of their use, obtained during the extraction of advertising texts aimed at professionals and nonprofessionals.

The material was obtained by sampling from Russian popular science texts of economic content (analyzed about 2500 contextual uses of the corpus of vocabulary), advertising texts of economic orientation (about 1300 contexts). The selection was carried out from two groups of texts: 1) texts of special dictionaries; 2) texts of industry literature, which served as a material for verification and correction of lexical units selected from dictionaries, works of economists, authentic texts from Newspapers and magazines over the past five years: 2014-2019. The source of the factual material was the dictionary entries of economic, financial and commercial dictionaries, as well as 
samples of economic articles from Russian, English and French magazines and Newspapers over the past fifteen years. In total, about 5 thousand units were analyzed in total.

Methods and methods of research are chosen considering the specifics of the object, goals and objectives of the study. The method of component analysis, as well as methods of conceptual contextual and comparative analysis, functional, contextual, component, structural-semantic, synchronouscomparative were used. In addition, such research procedures as hypothetical-deductive method, inductive method, method of definition analysis, elements of cognitive interpretation of A. N. Baranov [25], method of cognitive scenarios of A. N. Baranov are used in the work, Wierzbicka [26]. At the same time, the study used the method of content analysis [27] to identify the content side of advertising texts of mass media; discourse analysis, which studies the structure and units of discourse, the main of which is the speech act, as well as a comprehensive approach to the analysis of mass-media texts by analogy with the approach of F. Burkhardt [28] to the analysis of economic advertising texts, consisting in the study of their semantics, pragmatics, syntactics.

\section{RESULTS}

Modern economic concepts are widely implemented in metaphors, because over time and with the change of socioeconomic conditions have received new characteristics. The new era of economic change in the world has generated and continues to deliver new economic concepts, which are in the stage of formation and verbalized with the help of metaphors. And we see the study of this aspect very promising.

The post-industrial era, in which Russia enters with the whole world, demands speed, efficiency and inconstancy, more precisely, change, continuous change. The new paradigm of society and the individual puts the thesis at the top of the table that not everyone in a person is socially determined (remember the classic "environment jammed!"), irrational and even apocalyptic ideas are recognized as important: fate, chance, spirituality. The hypothetical opportunity to become richer is propagated much more resolutely than the thirst for social equality that has been cultivated in our souls for 70 years. Democracy proclaimed in the country is naturally mated with freedom of action, freedom of personal initiative and entrepreneurship, designed to ensure the rapid creative flourishing and maturity of the country, along with regular consequences of this, positive changes in attitudes and moods dictated primarily by the free market economy, the restructuring of social psychology is accompanied by negative overlaps. It originated, for example, as the London "Sandy Times" recently noted, a whole class of citizens who, apparently, perceive democracy as an opportunity to do whatever they please. The result is expressed in the word "lawlessness", which today often sounds throughout Russia.

The modern (multidisciplinary) stage of economic development, which is characterized by increasing requirements for the objectivity of the results of scientific knowledge in the context of expanding the scope of application of cognitive principles, has generated an increased interest in the logical-mathematical and semantic side of the accuracy of knowledge. This is due to the transfer of the center of research in gnoseological problematics to knowledge itself, and specifically to the area of the relationship of knowledge and the subject of knowledge, interpretation, etc. This implies the need to analyze the logical structure of knowledge, the ways of explication of concepts, prerequisites, problems and limits of knowledge, analysis of language and human factors in scientific knowledge [29].

The study of linguistic means of economic theoretical knowledge contributes to the solution of a number of current problems, the correct formulation and analysis of which require proper economic, natural science, mathematical, social and other knowledge. The language of economics is specifically historical, and therefore its understanding implies an understanding of economic terms, categories, schemes, rules, etc., which outline the boundaries and internal structure of the language world as final and historically limited [30].

The largest group is represented by anthropocentric models that allow us to identify and evaluate the events of economic life through comparison with the person himself and everything that is in his immediate environment. The common ground of reinvention is the Foundation for structuring economic reality through metaphors. It should be noted that the choice of signs that fill the metaphorical models of Russian, English and French languages is not always invariant. We explain the existence of options stereotypical attitude and perception of linguistic and cultural community. This process can be clearly traced through the analysis of models based on symbols (especially zoo-and color symbols). The study of semantics demonstrates the chain of relations person $\rightarrow$ sign $\rightarrow$ meaning $\rightarrow$ meaning $\rightarrow$ reality of the world of Economics.

The development of the concept of a scientific economic term in the semantic aspect is connected with the analysis of its essence and the change of its meaning in connection with the historical reconstruction of medical knowledge, with the relationship between the meaning of the term and theory, the scientific term and the object indicated by it, the semantics is studying the relation of objects and expressed content to build a good system of terms, one should use language constructions that are sufficiently far from us that would look flat, they wouldn't give volume, but they would be just badges" [5].

Language is a product of collective labor in all environments, directions, and personalities. It is an integral and integral part of the culture and the Russian language space. The Russian language has always been extremely receptive and extremely complimentary to foreign words: it absorbed French-language vocabulary in the 19th century and the Turkic languages 700 years ago, assimilating the numerous Anglicisms of the last years.

The material side (the plane of expression, meaning) of the metaphor as a sign is represented by words or phrases. The analysis of dictionary entries of special dictionaries (economic, financial and commercial, etc.) speaks about the growing potential of metaphors. There is a tendency to interpret well-known word formations without the use of litters. New meanings are given to simple words (créneau, niche; freeze prices), complex (carte Blanche; usufruct), collocations (vente à la boule de neige "avalanche" sale), including those using proper names (Renault, Chicago boys).

And here arises the main problem. One of the main causes of economic and ideological turmoil was the impossibility of adequate conversation in one language due to confusion of concepts, and sometimes just their substitution. Moreover, it often seems that terminological confusion is 
supported by politicians to increase the zone of incompetence and freedom of maneuver.

The Russian language provides great opportunities for playing with meanings and fixing non-obvious, irrelevant meanings. This quality can be used for moral sanctioning of many forms of economic behavior. Thus, the word "rich" ("bogatiy" - rus.) be a characteristic of approaching God (Bog - in rus.), and the neologism of "investing" - as a description of the process of moral commitment when investing capital. But at the same time, one cannot limit oneself to archaisms, not to use the dialogue between the meanings of old and modern, Russian and foreign-language (including Semitic, Turkic and other) terms and turns. In Russian historical vocabulary, it is not the vocabulary of Muscovite Russia that will inevitably come to the forefront, but the peripheral ones - Novgorod and Old Believers language strata traditionally used by reformers, starting with the Decembrists.

Research at the level of syntactics suggests that many terms of the language of Economics are formed by transferring meaning from special fields of knowledge: science and technology, religion and mythology, card games and sports (dismantling, shift, outsider, impasse "dead end", enfer "hell"). Some signs are accompanied by the marks "colloquial"," humorous", "negative" "disapproving" "slang", "vernacular", "high", "ironic", "contemptuous" (shark, feeder, mavrodiki (onoma - Mavrodi), pilot, vertebrate law).

The new life of words is characterized as an "avalanche" word formation, which is manifested not only in the number of new meanings in the " old "words, but also in the formation of" nests" of derived words, reflecting the actual concepts of the new time and subject to trends peculiar to the studied languages. This process is most clearly manifested in the Russian language. Here the activation of word-forming affixes is active. At the same time, intensive democratization of the language is gaining momentum, when reduced vocabulary is neutralized and allowed in the dictionaries of normative vocabulary: wooden-woodenity and other.

Aggressive securities - securities in the form of stocks, bonds, etc., the rate of which can significantly increase according to the observed situation in the stock market, trends, forecasts. Such papers are usually acquired in the expectation of obtaining significant profit, but their purchase is accompanied by a great risk, since the rate may fall.

For the practical implementation of management functions, structural units are specially created: committees and services that form the structural and functional composition of the management system. Such an approach reflects the distribution of functions in a cluster and defines a management system as a special organization of specialized management elements, combined into a single whole and designed to solve cluster problems, built on the principles of cooperation and specialization. It is assumed that the services perform special functions for the entire cluster or functional area (for example, accounting, auditing, etc.), and the committees coordinate the work of individual actors.

Portable values are always motivated. The reasons that caused the transfer of meaning at the time are usually " erased" from memory and can only be detected etymologically. But time can also lead to the revival of metaphor, as exemplified by the Masonic metaphors used today to characterize the creation of the European Union: $l a$ construction européenne, European construction, édifier, bâtir, construire l'europe.

The analysis of dictionary entries shows that the metaphorical representation of economic life is most often based on ideas about simple earthly relations. Figurative meanings relating to the field of Economics are observed in words denoting the most famous concepts from the immediate environment of a person: family, famille, corbeille, basket, fork, fourchette, threshold, seuil.

When combining signs of natural language within the Syntagma there is a loss of the original meaning of one of the elements of the Syntagma. For example, in the phrase serpent monétaire, currency "snake" the word monétaire, currency retains its meaning as defining monetary relations, and the word serpent "snake" loses its primary meaning. The original meaning may be lost in both elements of the Syntagma. Thus, in the phrase "shark watcher" (consulting firm), the first word observer changed its meaning from an animate subject to an inanimate object by similarity of functions (observe). The second word shark, by analogy with predatory marine fish, denotes a large firm that can absorb, which, accordingly, requires observation.

Economic term is a metaphor formed by a combination of more than two elements, syntagmatic relations between them correspond to the grammatical rules of combining words in Russian (French): "dead cat bounce" (a temporary rise in the stock market); "valeur de père de famille"/ "treasure dad" (a type shares).

Metaphorical consequences explicating the following relations are revealed in the economic vocabulary:

1) genus-species (human-player, donor, night watchman, gendarme; vehicle-ship, locomotive, train);

2) whole-part (mechanism-nut, screw, lever, lever; organism-skeleton, coeur; house-roof, supporting structure, plafond);

3) explication properties (organism-disease, pregnancy, strong organism, robuste, chétif; weather-storm, cold, orage);

4) explication of function (person-birth, walking, marche; vehicle-movement, stop, démarrage).

The same word can develop meaning in two directions. Thus, the word portfolio within one paradigm forms a metaphor: a portfolio of orders (proposals, problems). Within the Syntagma, this word contains in its metonymic meaning an addition and clarification (portfolio as an indication of a position requiring the use of a portfolio): to receive the portfolio of a Minister, the distribution of portfolios.

Thus, the picture of the studied economic reality turns into a special link of the developing scientific knowledge, which is closely in contact with the meanings of the universals of culture and has a worldview status. Thus, in the language of Economics, the designations transparency of the market; elastic market; l'inélasticité de la demande, la transparence de l'activité économique, etc.

An important parameter in the structure of metaphorical economic terms is the basis of the transfer value, which is determined by the ratio stored in the memory representation of objective reality with such a parameter, referred to economic concepts, which a common feature is compatible with it. Finding this parameter is possible when studying the "raw material" from which the meaning of the word is created. 


\section{CONCLUSION}

This study comprehensively and fully presents the algorithm of interaction between Linguistics and Economics. The axiomatics relating to the social mechanisms underlying economic activity goes beyond the limits of economic theory proper. Here we have to turn to the theoretical understanding of empirical data on the nature of social mechanisms emerging in the course of the Russian transformation. A public organization can be translated from the language of one culture into another, and the task of perceiving or recreating market concepts is solved within a completely different research program than in the case of an emphasis on the reconstruction of the corresponding meanings.

What is happening in political, economic, social and cultural life not only reflects on our language, but also grows into it, evolves, transforming the most subtle cultural impulses. This is the environment and the state of the cultural space ... Language is a product of collective labor, in all environments, directions, and hypostases. It is an integral and integral part of the culture and the Russian national space.

In principle, two large areas of discourse can be distinguished economic discourse: business communication (eng. business communication, corporate; communication; French. la communication d'entreprise; Rus. Delovaya kommunikatsiya or biznes kommunikatsiya) and advertising (eng. advertising; fr. la publicité (pub), la réclame; rus. reklama). We may use various forms of advertising. Here we see such types of advertising as monologue advertising, namely outdoor advertising (posters, banners, advertising in public transport), advertising, radio advertising, television advertising, advertising on the Internet. In addition, direct advertising, in which potential customers act purposefully, as part of direct mail. It should be borne in mind that the dialogical forms of advertising appeal and business negotiations on the purchase are different [31].

To identify and describe the lingual grammatical specificity of texts on the enterprise plays a decisive role in the description of pragmatic context, which makes necessary their review as "economic texts - in - action - and - in situation" and the consideration of aspects of economic discourse (communication) in the enterprise and description of its parameters ultimately determine the linguistic processing of texts of reports on the activities of the enterprise.

From the point of view of non-linguistic specificity, the report on the activities of the enterprise is a written monological form of communication in the enterprise, the main function of which is an informative function. A distinctive feature of reports on the activities of the enterprise is their developed metagraphemics, which is expressed in the active use of visual signs: tables, graphs, diagrams, photographs. The result was the conclusion about the semiotic complexity of the economic texts of reports, why the entire text of the report on the activities of the enterprise can be considered as a "pictorial-textual conglomerate".

The degree of terminologization allows us to speak about a special language, or the language of a special area, which does not exist in itself as a separate system but is updated in special texts.

The theoretical significance of the work relates to the further development of the problem of integration of Sciences. The findings contribute to the expansion of existing ideas about the role of Economics in life and the linguistic picture of the human world. In addition, the analysis of the" inner content "of economic terms in everyday and professional language consciousness makes it possible to present the term as a multidimensional linguistic reality, rather than a "emasculated word".

The practical significance of the study stems from the potential possibilities of science for universalization, primarily contained in its integrated nature. Practical research material can be used in the analysis and interpretation of any scientific texts. The description of the presentation of economic terminology in the modern advertising discourse will reveal an objective picture of its functioning in the modern language consciousness and build a projection on the future of linguoeconomics. The obtained results can be useful for typological research of sublanguages of science and technology, terminology, private methodology and General theory of lexicography. This research can be used for the universities, teachers, and students.

\section{LIMITATION AND STUDY FORWARD}

Economic Linguistics itself is different from systemic linguistics. Language manipulation today can be implemented through study of special economic communication processes $[7,32,33]$. For image text questions-Communication or even intercultural communication is just in the sphere of economic communications. The future task of linguistic-economic discourse will be to select language means for presentation/ sale of goods with particular care. The interaction of national, national or ethno-cultural, corporate-cultural and even situational discourses takes place in the details of linguistic-economic discourse, especially with key words, terms, hybrid forms of oral and written language, as well as persuasive strategies. Linguistic and economic discourse today is expanding and turning into a variety of types of discourse: political, scientific, household, mass-media, religious. Discourse diffusions are preferred from economic dysfunction.

Unlimited possibilities of a combination of signs at combination and creation of complex economic metaphorical terms testify to their high informationsemiotic potential, wide creative possibilities of human reason, openness and incompleteness of knowledge, about ability to dream and make unexpectedly exact comparisons, being based on those signs which are chosen by consciousness of the person to learn and define "concepts escaping from reason".

\section{REFERENCES}

[1] I.S. Karabulatova, S.V. Kulikov, A.R. Yanguzin, O.B. Barabash, Mythological codes in modern television discourse/ Códigosmitológicos en el discursotelevisivo modern, Revista de Filosofia 2 (2017) 183-192,

Available at:

http://produccioncientificaluz.org/index.php/filosofia/arti cle/view/23964/24425.

[2] I. Karabulatova, Kh. Vildanov, A. Zinchenko, E. Vasilishina, A. Vassilenko, Problems of transformation matrices modern multicultural identity of the person in the variability of the discourse of identity Electronic 
Information Society, Pertanika Journal of Social Science \& Humanities 25 (2017) 1-16, Available at:

http://www.pertanika.upm.edu.my/Pertanika\%20PAPER S/JSSH\%20Vol.\%2025\%20(S)\%20Jul.\%202017/JSSH( S)-0376-2017.pdf.

[3] Y. Privalova, N. Kashirina, A. Yakovlev, C. Gabidullina, Innovative Autonomous Language Education, Man in India 97(23) (2017) 419-426.

[4] V. Naishul, Economy-language-culture, Social Sciences and modernity 6 (2000) 33-35.

[5] G. Khazagerov, Economy-language-culture, Social Sciences and modernity 6 (2000) 37-39.

[6] E.F. Kovlakas, Semantic aspects of market and economic terminology, Krasnodar, 2003.

[7] A.R. Sulkarnaeva, Attomatically secondary nomination in the technical terminology (in English and Russian languages), Almaty, 2006.

[8] N.D. Arutyunova, Language and the world of man, Languages of Russian culture, 1998.

[9] R. Jensen, Dream society: How the coming shift from information to imagination will transform business, 2004.

[10] H. Siebenschein, Abhandlungen zur

Wirtschaftsgermanistik, Orbis, 1936.

[11] L. Drozd, W. Seibicke, Deutsche Fach- und Wissenschaftssprache, John Benjamins Publishing Company, 1973.

[12] N.R. Sayenko, A.A. Sozinova, I.S. Karabulatova, I.V. Akhmetov, O.V. Mamatelashvili, E.E. Pismennaya, Research in Action Integrated Marketing Communications as the Elements of Information and Virtualization Market Relations, International Review of management and marketing 6(1) (2016) 267-272.

[13] O.M. Maksyutova, Language means of realization of a pragmatic attitude in the British press (on the material of the headline as a component of the newspaper text): dissertation ... candidate of philological Sciences, Moscow, 1984, 198 p.

[14] R.N. Putilina, The use of television in teaching foreign languages, Kiev. State Ped. Institute of foreign languages, 1986.

[15] E.K. Shibanova, Motivation of the personality of the head in collective decision-making, in: Actual problems of University science and education, Publishing house "Ural LTD", 2003.

[16] A.V. Stepanenko, Linguocognitive features of metaphor functioning in political discourse: on the material of the Russian and German languages: abstract of dis. ... candidate of philological Sciences, Moscow, Moscow state linguistic University, 2001.
[17] Sathyamurthi Karibeeran, Shefali Mohanty, Emotional Intelligence Among Adolescents, Humanities and Social Sciences 7(3) (2019) 121-124.

[18] Vu Hong Van, Beliefs Worship the Village's Tutelaray God in the Beliefs Life of Vietnamese People, Humanities and Social Sciences 7(3) (2019) 156-164.

[19] I. Oleksiewicz, Policy to Prevent and Combat Cyber-crime in Africa, Humanities and Social Sciences 7(3) (2019) 138-146.

[20] H. Priono, I. Yuhertiana, S. Sundari, D.S. Puspitasari, Role of financial management in the improvement of local government performance, Humanities \& Social Sciences Reviews 7(1) (2019) 7786. DOI: https://doi.org/10.18510/hssr.2019.7110

[21] S.L. Ratnasari, G. Sutjahjor, Adam, Employees' performance: organizational culture and leadership style through job satisfaction, Humanities \& Social Sciences Reviews 7(5) (2019) 597-608. DOI: https://doi.org/10.18510/hssr.2019.7569

[22] H. Meddour, O. Saoula, A.H. Abdul Majid, M.A. Abu Auf, Effects of top management support on knowledge transfer and sharing: the mediating role of trust, Humanities \& Social Sciences Reviews 7(1) (2019) 189-198. DOI: https://doi.org/10.18510/hssr.2019.7123

[23] O.A. Koryakovtseva, I.I. Doronina, T.M. Panchenko, I.S. Karabulatova, Z.M. Abdullina, Research of category "Motivation" as a basic tool of personnel management, International Review of Management and Marketing 6(1) (2016) 293-299.

[24] S.A. Khakhalova, Category of metaphoricalness: Forms, means of expression, functions: thesis ... doctor of Philology, Irkutsk, 1997, 447 p.

[25] A.N. Baranov, Linguistic expertise of the text, Flinta, 2007.

[26] A. Vezhbitska, Semantic universals and description of languages, Moscow, 1999.

[27] B. Mannheim George, R.K. Rich, Political science: research Methods, Publishing house "the Whole World", 1997.

[28] F. Burkhardt, Sprache in der Politik: Linguistische Begriffe und Methoden, Englisch-Amerikanische Studien 10(3/4) (1988) 333-358.

[29] G.A. Shiganova, I.S. Karabulatova, A.V. Sviridova, L.P. Yuzdova, The concept of "Knowledge"/ "Cognition" in Russian paremia: the experience of structural semantic representation, Astra Salvensis 6(12) (2018) 385-393.

[30] L. Shkvarya, I. Karabulatova, V. Rusakovich, A. Rapiev, The impact of the customs union and the EAEU on the small and medium business in Kazakhstan, Central Asia and the Caucasus 18(1) (2017) 93-100. 
[31] M.V. Bykova, Economic language and the area of its use, in: Linguistics. Training. Culture: Collection of articles. Issue 1, Pomeranian University, 2007.

[32] H. Kuße, «Verantwortung» im Wirtschaftsdiskurs. A. Filáček (Hrsg.), Věda, filosofie, metodologie. Sborník k 85 narozeninám prof. Ladislava Tondla [Wissenschaft, Philosophie, Methodologie. Festschrift zum 85

Geburtstag von Professor Ladislav Tondl]. Filosofia, 2009.

[33] M.R. Zheltukhina, O.S. Ryabova, On the crosscultural specificity of the economic interview in the printed mass-media: the science of translation aspect, Business. Education. Law, Bulletin of Volgograd Business Institute 3 (2007) 119-124. 